CONTRA O "AR RAREFEITO DA TEORIA MORAL"

\author{
AGAINST THE “THIN AIR OF MORAL THEORY”
}

\author{
JANYNE SATTLER ${ }^{2}$ \\ (Universidade Federal de Santa Catarina, Brasil)
}

\begin{abstract}
RESUMO
O diagnóstico já fora dado por Wittgenstein ele mesmo, tão cedo quanto no Tractatus e mais claramente ainda nas Investigações Filosóficas: a urgência em se resolver certos "problemas fílosóficos" não passa de um sintoma de doença filosófica. Poderíamos mesmo dizer que a principal preocupação de Wittgenstein ao longo de seu trabalho era aquela de fornecer um tratamento filosófico eficiente para a cura das ilusões do filósofo e um método (ou alguns métodos) para se determinar uma nova atitude filosófica por meio de uma nova atividade filosófica. Tanto o diagnóstico quanto o tratamento sugerido tiveram um enorme impacto sobre a reflexão filosófica contemporânea, a qual eu gostaria aqui de considerar desde o ponto de vista da assim chamada "filosofia moral", cujo destino é a questão deixada em aberto por este artigo. No que se segue, eu vou começar por uma breve caracterização da referida atitude wittgensteiniana tal como aplicada a alguns autores: Anscombe, Gaita e Elliott, sobretudo; e tentar esboçar uma imagem de uma atividade filosófica que é principalmente (e moralmente) terapêutica; este quadro será então completado com a crítica compartilhada por estes autores à "filosofia moral tradicional" tal como primeiro e claramente atestada por Anscombe; finalmente, tentarei esboçar e exemplificar algumas das possibilidades alternativas abertas ao destino da "filosofia moral" contra a mera exegese e contra uma atitude academicista e pedante que parece estar sempre à espreita em nossas incursões normativas.
\end{abstract}

Palavras-chave: Wittgenstein. Moralidade e 'filosofia moral'. Gaita. Elliott.

\begin{abstract}
The diagnosis was already given by Wittgenstein himself, as early as in the Tractatus, and more clearly so in the Philosophical Investigations: the urge to solve certain "philosophical problems" is but a symptom of a philosophical disease. We could indeed say that Wittgenstein's main concern all along his work was to furnish an efficient philosophical treatment to cure the philosopher's illusions and a method (or some methods) to establish a new philosophical attitude by means of a new philosophical activity. Both the diagnosis and the suggested treatment had an enormous impact on contemporary philosophical reflection, which I would like to consider here from the point of view of the so-called "moral philosophy", the fate of which is an open question to be reflected on in this paper. In what follows I will begin with a brief characterization of the referred Wittgensteinian attitude as it applies to some authors: especially Anscombe, Gaita and Elliott; and to try to draw a picture of an anti-theoretical and anti-metaphysical moral-philosophical activity; this picture will then be completed with the authors shared criticism of traditional moral philosophy - as first and clearly stated by Anscombe; finally, I will try to delineate some of the alternative possibilities open to the future of "moral philosophy" against mere exegesis and against the old, pedantic - and always haunting - purely speculative attitude.
\end{abstract}

Key words: Wittgenstein. Morality and 'Moral Philosophy'. Gaita. Elliott. 
O diagnóstico já fora dado pelo próprio Wittgenstein, tão cedo quanto no Tractatus, e mais claramente ainda nas Investigações Filosóficas: a urgência em se resolver certos "problemas filosóficos" não passa de um sintoma de doença filosófica. Poderíamos mesmo dizer que a principal preocupação de Wittgenstein ao longo de seu trabalho era aquela de fornecer um tratamento filosófico eficiente para a cura das ilusões do filósofo e um método (ou alguns métodos) para se determinar uma nova atitude filosófica por meio de uma nova atividade filosófica. Tanto o diagnóstico quanto o tratamento sugerido tiveram um enorme impacto sobre a reflexão filosófica contemporânea, a qual eu gostaria aqui de considerar desde o ponto de vista da assim chamada "filosofia moral".

É Elisabeth Anscombe, com seu artigo Modern Moral Philosophy (1958), quem primeiro estabelece o cenário para um novo tipo de proposta na esfera da ética. Mostrando o quão pobres e o quão equívocas são as teorias morais, principalmente kantianas e consequencialistas, Anscombe clama por alternativas mais ricas. De fato, é de amplo conhecimento que a ética de virtudes contemporânea desenvolve a crítica de Anscombe em direção a uma nova abordagem da moralidade - e isso por si só já me parece constituir um ganho relativamente às teorias morais "legalistas" tradicionais. ${ }^{3}$ Mas meu maior interesse é aqui explorar aquelas propostas alternativas que compartilham com Anscombe, mais do que uma posição teórica positiva como aquela da ética de virtudes, na verdade a sua atitude wittgensteiniana. Eu gostaria de olhar um pouco mais de perto para aqueles autores que são "wittgensteinianos em espírito", mas que não possuem nomes próprios para as suas reflexões correntes. Eu penso aqui sobretudo em Raimond Gaita e Carl Elliott. Claro, em primeiro lugar devemos tentar entender o que significa falar de "wittgensteiniano em espírito" neste contexto em particular. E eu gostaria de trazer aqui a sugestão de que um dos traços mais marcantes desta atitude é o seu posicionamento contra uma "filosofia moral tradicional" vista de ponta a ponta como metafísica, teórica e normativamente comprometida. ${ }^{4}$

A influência de Wittgenstein sobre estes autores não concerne, assim, um conteúdo específico, mas principalmente a "forma" dada à reflexão filosófica, ao se negar aí a força do argumento puramente racional, da construção puramente teorética, da moralidade univocamente baseada em princípios, de definições definitivas, de investigações puramente acadêmicas e institucionalizadas. Tais autores requerem, portanto, uma abordagem da moralidade que seja mais flexível e acomodativa e, ao mesmo tempo, mais complexa, e que não seja inteiramente compreendida pelos compromissos legalistas feitos em nome de uma "filosofia moral" - e isto, mesmo no caso de algumas teorias da ética de virtudes, muito embora estas possuam pontos de contato com questões centrais para a alternativa aqui em pauta. Esta é a razão pela qual os autores aqui considerados atribuem à literatura um papel tão importante para a reflexão moral, e 
a razão pela qual eles se colocam contra a mera exegese filosófica - inclusive a mera exegese wittgensteiniana.

Com este quadro em mente, o meu objetivo é refletir sobre o destino de uma filosofia moral que se queira como tal dentro do escopo destas propostas wittgensteinianas. Se Jacques Bouveresse (1984) está correto em insistir que a filosofia acadêmica continua infectada pelas mesmas doenças há muito diagnosticadas por Wittgenstein - junto com um certo desespero e um certo ceticismo, mas também com um orgulho e esnobismo arrogantes - então as alternativas à reflexão moral aqui almejadas podem constituir uma parte de uma terapia voltada à cura de certas ilusões filosóficas sobre a moralidade - principalmente aquela de um convencimento final e permanente por meio de argumentos. ${ }^{5}$ Estaria então o "futuro da filosofia moral" assentado sobre abordagens fluidas (narrativas e literárias) da moralidade? Tanto Elliott quanto Gaita responderiam positivamente a esta questão.

No que se segue, eu vou começar por uma breve caracterização da referida atitude wittgensteiniana tal como aplicada aos autores aqui mencionados: Anscombe, Gaita e Elliott (aos quais poderíamos também acrescentar Cora Diamond, Alice Crary e John Gibson, entre alguns outros); e tentar esboçar uma imagem de uma atividade filosófica que é principalmente (e moralmente) terapêutica; este quadro será então completado com a crítica compartilhada por estes autores à "filosofia moral tradicional" tal como primeiro e claramente atestada por Anscombe; finalmente, tentarei esboçar e exemplificar algumas das possibilidades alternativas abertas ao destino da "filosofia moral" contra a mera exegese e contra uma atitude academicista e pedante que parece estar sempre à espreita em nossas incursões normativas. Afinal, Wittgenstein nos alertou cedo o bastante quanto àqueles "problemas filosóficos" irrespondíveis (e, portanto, sem sentido e supérfluos). A "filosofia moral" parece estar demorando tempo demais para levar este alerta a sério.

\section{A atitude wittgensteiniana}

Sem dúvida, eu tenho interesse em uma exegese wittgensteiniana e há muita coisa que eu ainda gostaria de escrever a respeito dos objetivos éticos do Tractatus, por exemplo, ou sobre o difuso conceito de 'estética' tal como ele aparece nas chamadas obras intermediárias de Wittgenstein - e eu tenho de fato alguns projetos em andamento relativos a estes tópicos específicos. Mas ao pensar acerca das mais importantes contribuições de Wittgenstein à filosofia, me vejo diante de uma imposição que toma as suas lições muito mais a sério, e que é aquela que se afasta da mera revisão e comentário - lições estas que nos permitiriam parar de "filosofar" quando bem quiséssemos. ${ }^{6}$ Eu gostaria de pensar a compreensão destas lições em termos de uma tomada de atitude a partir da qual emoldurar uma reflexão sobre a moralidade que seja aberta e flexível, mas lúcida e comprometida ao mesmo tempo. 
Naturalmente, esta atitude é ela própria caracterizável a partir de traços wittgensteinianos - e esta me parece ser de fato a influência mais fecunda de Wittgenstein sobre o pensamento filosófico contemporâneo: o arcabouço de um certo tipo de reflexão, o compartilhamento de uma certa atitude ou espírito em vista de uma clara, perspícua e aquietada atividade filosófica como se verá abaixo.

Por razões de espaço, vou me abster de citar o próprio Wittgenstein para oferecer a seguir um retrato mais amplo desta atitude ou espírito de fundo sobre o qual se inscrevem os autores subsequentemente mencionados. ${ }^{7}$

Em primeiro lugar, há aí a rejeição de uma certa postura metafisica cuja busca se dê por uma fundação qualquer, por uma essência do mundo (das coisas, da linguagem, do valor), e por uma solução filosófica conclusiva, salvadora e libertadora; ela é uma atitude anti-metafísica na medida em que não almeja estender-se para além das forças do filósofo em vista de uma universalização e, muitas vezes, de uma racionalização; ela é profundamente crítica das tentativas da filosofia de encontrar "soluções finais" ou um qualquer "progresso filosófico"; afinal, não pode haver progresso ou resultado quando se trata de uma profundamente incompreendida "perplexidade filosófica" que deve restar aberta a um outro tipo de vivência, como também não pode haver respostas para problemas vazios cuja própria formulação é, antes de mais nada, equivocada.

De modo relacionado, há aí a rejeição de uma certa postura teorética: a filosofia não deve proceder à defesa de teses à maneira das ciências, e não deve constituir-se ela mesma em uma doutrina, uma teoria, um sistema, um manual de princípios; esta razão está ligada igualmente à rejeição de dogmatismos mais ou menos assumidos e ao fato de que o objetivo da filosofia deve ser a clareza diante da ausência dos "problemas filosóficos". Claro, continuamos escrevendo livros e reunindo nossas ideias em artigos e apresentações de simpósios; mas não poderia também isso aproximar-se mais de uma atividade filosófica do que figurar como o edifício supostamente conjunto de uma defesa sistemática, por parte de uma restrita sociedade acadêmica, de algum tipo de resposta (teórico-normativa)? De fato, a compreensão da filosofia como uma atividade é um outro traço ainda desta atitude wittgensteiniana, e que não pode ser vista em separado de sua qualidade terapêutica - cuja ênfase já está presente no parágrafo 4.112 do Tractatus, e passível de encaixar-se na pluralidade de métodos tal como vislumbrada pelas Investigações. Evidentemente, a terapia aqui em questão visa antes de mais nada identificar aqueles sintomas metafísicos, teóricos e dogmáticos típicos de uma doença filosófica - o afastamento da visão problemática do mundo constituindo por si só um passo em direção à cura.

$\mathrm{O}$ ponto de intersecção entre os autores aqui mencionados reside precisamente no fato de que esta atitude requer tal flexibilidade (de pensamento, de escritura e de exposição reflexiva) que desde o início se rejeita a pretensão de uma sistematicidade teorética, de uma univocidade 
de sentido e de definições peremptórias. Sua reflexão filosófica é uma atividade que almeja chegar, através de procedimentos terapêuticos, a uma perspectiva mais lúcida sobre a vida (sobre a vida moral), e sobre a própria filosofia. Sendo assim, este gênero de reflexão ativa e terapêutica só pode ser adequadamente contemplado se a questão da variabilidade for igualmente aplicada à sua metodologia. Dito de outro modo, esses autores "wittgensteinianos" não apenas endossam a concepção de Wittgenstein da filosofia como atividade e a compreensão de Wittgenstein da filosofia como compromissada com diferentes formas de terapia e método, como empregam e aplicam estes mesmos traços à sua própria empreitada filosófica. De que outra forma mostrar a importância desta herança senão na realização e na incorporação destes caminhos alternativos de se escrever (e de se fazer) filosofia?

E já que uma nova escritura constitui ainda uma outra característica da atitude wittgensteiniana, importa grandemente para a conquista terapêutica, a maneira de se abordar os "problemas filosóficos". O ponto não é a busca por definições, explicações, fundamentações ou justificações últimas, mas buscar ver claramente através da massa de ilusões e de pretensões que têm confundido a filosofia há já tanto tempo; trata-se então de buscar ver as coisas sob uma nova luz, e desde vários pontos de vista, e conscientemente "colocar as coisas lado a lado" $8 \mathrm{em}$ prol da perspicuidade. Para esses autores, tudo isso pode inclusive significar colocar a filosofia lado a lado com a literatura.

E não demandaria isso, novamente, uma maneira completamente diferente de se abordar os "problemas filosóficos" na medida em que, se legítimos, são reconhecidos como complexos, exigindo respostas também complexas ao invés de simples e unívocas, e considerações mais ricas e detalhadas ao invés de unilaterais e parciais, e uma percepção multifacetada ao invés de tendenciosa e previamente, teórica e normativamente, comprometida? Afinal, não é a nossa reflexão levada a cabo justamente "no meio das coisas"? ${ }^{9}$ E não é a vida (e a vida moral) ela mesma complexa e repleta de detalhamentos e riquezas impossíveis de se dizer de uma vez por todas? Como é que poderíamos de fato tentar emparelhar essa vida com a singularidade, a incondicionalidade e a abstração? Como é que poderíamos de fato compreender essa vida desde uma visão de mundo confinada a uma posição estanque (emprisionada sobretudo por uma teoria ou pela clausura de uma norma)? Tal como a própria vida, refletir e escrever (sobre moralidade, em nosso caso) requerem flexibilidade, abertura e comprometimento para com um mínimo de claridade, lucidez e seriedade.

E assim, multiplicidade, complexidade e riqueza, da vida e da metodologia e reflexão filosófica, são os últimos traços desta atitude os quais eu gostaria de acrescentar a esta lista (não exaustiva, contudo). 


\section{A crítica à "filosofia moral tradicional"}

O meu interesse é agora indagar, ainda que de modo inicial, sobre o modo como esta "atitude wittgensteiniana" pode nos ajudar a encontrar o nosso caminho na esfera da moralidade.

Eu não pretendo aqui resumir ou analisar as razões dadas por Anscombe para se banir "a ética de nossas mentes" enquanto esperamos por uma adequada filosofia da psicologia, ${ }^{10}$ mas tomar o seu texto como um primeiro passo em direção a uma nova maneira de se pensar sobre a vida moral. Se sua influência é indubitavelmente wittgensteiniana, a sua própria posição firme e radical a propósito do esvaziamento dos conceitos da filosofia moral moderna mobiliza, por um lado, o renascimento da ética de virtudes e, por outro lado, a busca por um modo verdadeiramente destemido de se pensar a moralidade - mas "destemido" não no sentido de se permitir o mal e a injustiça como desenlace possível dos princípios morais legalistas (sobretudo consequencialistas) levados às suas últimas consequências, mas no sentido de se admitir a complexidade como um traço inescapável da vida humana e de se reconhecer, com isso, a impossibilidade de qualquer teoria que possua um objetivo e um critério normativo singular e pretensamente universal (para a vida moral). ${ }^{11}$

Se Martha Nussbaum, Iris Murdoch e Cora Diamond, cada uma a sua maneira, são filósofas que podemos mencionar como herdeiras do texto inaugural de Elisabeth Anscombe, ${ }^{12}$ neste momento eu gostaria de tomar como modelo e exemplo de uma posição alternativa em reflexão moral outros dois filósofos que se inscrevem naquele segundo desdobramento descrito acima: Raimond Gaita e Carl Elliott. ${ }^{13}$

Gaita e Elliott são ambos profundamente críticos de uma "filosofia moral" como disciplina filosófica acadêmica. Inclassificáveis, as suas abordagens são não obstante "wittgensteinianas em espírito" e amplamente abertas à literatura como "terapêutica" (sobretudo no sentido de fazer ver mais claramente aquilo que a filosofia não é capaz de mostrar) e metodologicamente mais rica do que nossas conhecidas teorias normativas. Guardadas as suas diferenças, ambos compartilham uma preocupação quanto ao "futuro" da reflexão moral, insistindo no esvaziamento (e às vezes até mesmo no mal) de se pensar pelo bem do argumento. Ademais, ambos performatizam suas novas abordagens da moralidade em sua própria escritura, tomando o seu devido tempo para exibir uma complexa visão de mundo, exigindo do leitor um comprometimento e um engajamento completamente novo "em seu próprio nome", desde sua própria perspectiva e pelo bem de sua própria convicção moral.

Se pudesse, Gaita evitaria até mesmo os termos (metafisicamente) carregados de 'ética' e 'moralidade' ${ }^{14}$ E esta é a razão pela qual ele insiste em fazer uso de expressões menos definidas e mais abertas tais como "compreensão moral" e "reflexão moral", em prol daquilo que ele deseja que seja "visto" como um todo - não, portanto, em prol de uma argumentação moral 
conclusiva em direção a uma norma. Afinal, a sua abordagem não toma parte em qualquer tipo de "sistema filosófico" e está continuamente aberta a descobertas, revisões e emendas. Uma lúcida e comprometida reflexão sobre o significado da vida moral requer, portanto, que possamos preencher as lacunas deixadas pela "filosofia moral tradicional" de um lugar completamente novo e flexível ao enfatizar a complexidade de nossa gramática "of a certain way of speaking of the meaning of a human life" (Gaita 2004, p.127). Daí a necessidade de se pensar sobre uma linguagem do amor, da verdade, do mistério, da bondade, do mal, do remorso, da realidade do outro: uma linguagem assumidamente mais próxima da arte, da poesia e da literatura do que da ciência e da teorização filosófica. Em um sentido bastante específico, suas considerações podem ser tomadas como "metaéticas" ao refletirem sobre o próprio conceito de 'moralidade' contra o pano de fundo deste fazer filosófico - e a questão que permeia suas obras de uma ponta a outra é justamente "o que significa e o que constitui de fato uma reflexão moral?" Que se possa tomá-la como uma atividade dada e indubitável é igualmente um ponto de crítica.

Os interesses de Elliott possuem pontos importantes de contato com a bioética, mas certamente não clamam por uma classificação teórica ou sistemática dentro desta área. Afinal, para esse autor a questão crucial é novamente saber o que conta como uma vida significativa uma questão anterior a qualquer consideração normativa ou que se proponha a decidir critérios de "conduta", de "ação", ou de escolha de "princípios" regulativos (mais ou menos legais). Dentro de um perspectiva que poderia ser ainda uma vez "metaética" em um sentido bastante particular, não se trata, portanto, da busca por uma teoria moral que venha a explicar o sentido da vida humana para fins de justificação, mas da aceitação da vida ela mesma como complexa, e dos "problemas" da vida como contextuais e circunstanciais - não podendo ser resolvidos por meio de uma determinação ou procedimento cirúrgico singular. Daí a ênfase dada por Elliott às descrições perspícuas e às narrativas em prol de diagnósticos e terapias bioéticas as quais poderiam contemplar um quadro mais amplo de significados a respeito de questões que são, muitas vezes literalmente, de vida ou morte. Assim como os escritos do próprio Elliott sobre o que significa refletir de maneira responsável (para com todos os envolvidos) em bioética, uma "terapia literária" (via romances, por exemplo), poderia apresentar ao leitor um novo tipo de "sensibilidade": ao mostrar que compreender a nossa própria vida moral é algo que toma tempo, que exige comprometimento, seriedade, lucidez, senso de humor, um sentido de humanidade compartilhada e, entre outras coisas, uma atitude atenta e cuidadosa para com o mundo.

\section{Possibilidades alternativas à "filosofia moral"}

Ao apresentar uma perspectiva herdada ao mesmo tempo de Wittgenstein e do ponto de partida dado com Anscombe, Raimond Gaita e Carl Elliott parecem oferecer o melhor dos 
cenários a partir do qual se pensar a respeito do destino da "filosofia moral". Um destino no qual abordagens fluidas e flexíveis da moralidade não precisassem ser vistas como suspeitas, mas como seriamente engajadas pela vida humana e por seu significado, bem como seriamente comprometidas em pensar o estatuto de nossa vida moral ela mesma. Ou é isso, pelo menos, o que eu gostaria de propor aqui.

Tendo como pano de fundo este espírito wittgensteiniano e as figuras de Gaita e Elliott e o exemplo performativo de suas obras, eu gostaria de propor a seguir um conjunto preliminar e não exaustivo de características a cumprir por uma reflexão moral séria e lúcida que se coloque em oposição àquilo que tenho chamado de clausura da norma. Trata-se de uma lista aberta, a qual pode vir a ser completada ou modificada no decorrer da própria reflexão tal como inserida neste estudo a longo prazo. No espaço deste artigo, estas caraterísticas devem ser suficientes para fazer ver o caminho aberto por esta alternativa.

Em primeiro lugar, havendo aí uma atitude wittgensteiniana tal como esboçada acima, está claro que esta reflexão moral não deve participar de uma investigação filosófica meramente exegética - seja esta exegese de Wittgenstein, de Gaita ou de Elliott, ou de outras. É claro que o que dizem estes filósofos importa na medida em que nos ajudam a esclarecer mal entendidos e ilusões filosóficas, e na medida em que podem nos oferecer uma certa compreensão compartilhada do estatuto da 'moralidade'. Mas o interesse dessas abordagens e das obras aqui citadas é o interesse de uma senda aberta por onde seguir caminhando - com eles, mas com nossas próprias pernas.

Em segundo lugar, dada a necessidade de abordagens mais fluidas para se pensar o que 'moralidade' realmente significa, a própria empreitada desta reflexão moral pode ser realizada através de formas alternativas de escritura e "argumentação" que estejam abertas a "narrativas filosóficas" 15 e à literatura - ou seja, uma forma de escritura que possa mostrar em si mesma a riqueza e a complexidade da vida moral. ${ }^{16}$

Tal performatividade poderia ser também uma maneira de nos ajudar a transformar o nosso modo de ver as coisas: um certo tipo de reflexão moral que nos ajudasse a ter "olhos para ver" e "um coração para entender". ${ }^{17}$ Não, portanto, um procedimento apenas de argumentação e exposição de conceitos abstratos, mas uma visão dada do "meio das coisas" e circunstâncias, a partir da realidade complexa da individualidade humana. Evidentemente, tudo isso significa que aprender a ver e a compreender "com o coração" é algo que indubitavelmente leva muito mais tempo do que conhecer e enunciar princípios ou critérios impessoais - também porque se trata de um aprendizado que é autoconhecimento.

A exigência de se ter "olhos para ver" e de se "tomar o seu tempo" é a exigência de uma vivência moral lúcida e engajada - que requer justamente, portanto, engajamento: trata-se, 
assim, em terceiro lugar, de refletir sobre a vida moral como "por sua própria vida", como às vezes ler literatura é também "ler pela vida". ${ }^{18}$

Neste sentido, esta perspectiva sobre o que significa "refletir sobre a moralidade" nos mostra novamente o quão próxima ela pode estar da literatura: da literatura como ferramenta fundamental para a compreensão da nossa própria vida moral, mas igualmente para a compreensão, em sua profundidade, da realidade dos outros. Ao autoconhecimento acrescentase, portanto, o conhecimento amoroso dos outros - ou da possibilidade de se amar os outros no reconhecimento de sua humanidade compartilhada. E, de fato, isso permitiria a cada um de nós - e não apenas ao filósofo acadêmico especializado - almejar por uma profunda "compreensão moral" (para usar a expressão de Gaita), sem que isso signifique a edificação de uma "filosofia moral" ou de uma "ética" (normativa).

Finalmente, para esta reflexão moral que se quer perspícua, séria e lúcida contra a clausura da norma, é ainda preciso compreender o papel que desempenham certos traços inescapavelmente humanos quando nos engajamos por nossa própria vida e pela vida dos outros. Também aqui não se trata de uma lista exaustiva, mas de uma primeira aproximação e da necessidade de salientar conceitos muitas vezes negligenciados pelas teorias morais normativas - e que se mostram cruciais para a composição de uma teia de significados constitutivos da própria 'moralidade'.

Os traços em questão são, antes de mais nada, aqueles que podem ser aplicados na caracterização da nossa vida moral tanto quanto na caracterização de nossas propostas metodológicas terapêuticas: complexidade, riqueza e flexibilidade. Em seguida, aqueles traços que também fazem parte da própria tarefa e atividade de leitura e reflexão: imaginação, empatia e emoção. Depois, amizade, amor, engajamento e comprometimento como aqueles traços que aprendemos com uma "leitura para a vida", por exemplo, mas que são obviamente ao mesmo tempo características imprescindíveis de uma vivência ou de uma experiência moral enriquecedora. Por fim, aqueles traços que nos possibilitam considerar a moralidade desde o ponto de vista de uma humanidade comum e compartilhada - um ponto de vista que reivindica necessariamente uma profunda responsabilidade pelo outro.

É claro que a mera menção destas características não contribui por si só para uma revisão dos conteúdos clássicos da filosofia moral tradicional, e não responde de imediato sobre o modo como elas podem contribuir para uma compreensão mais profunda sobre o significado da 'moralidade' de tal forma que esta não se veja reduzida ao enclausuramento da normatividade com o que se faz necessária uma reflexão mais detalhada, mais alongada e de maior fôlego, tanto sobre esta metodologia filosófica assim qualificada quanto sobre a descrição da nossa vida moral por meio de conceitos marginais às considerações acadêmicas vigentes. 
A proposta aqui esboçada deve, portanto, ser tomada como o rudimento de um trabalho em andamento. Também porque me parece pungente a necessidade de se reconsiderar o privilégio e a contínua centralidade da "filosofia moral moderna" e de suas propostas pretensamente universais, mas muitas vezes excludentes. Os autores aqui mencionados - em sua herança wittgensteiniana - me parecem poder ajudar no cumprimento dessa tarefa. Se suas obras manifestam já uma profunda mudança relativamente aos nossos modos de pensar as demandas da vida moral e os engajamentos responsáveis pela vida dos outros, mais trabalho há para ser feito, a começar por asseverar reiteradamente as lições de Wittgenstein contra a insistente ameaça de insulamento do mero academicismo. 


\section{Notas:}

${ }^{1}$ Este título faz menção a uma expressão usada por Carl Elliott na introdução de Slow Cures and Bad Philosophers. (Cf. ELLIOTT, 2003, p.05).

2 Professora do Departamento de Filosofia e do Programa de Pós-Graduação em Filosofia da Universidade Federal de Santa Catarina (UFSC), Florianópolis, Brasil. e-mail: janynesattler@yahoo.com.br

${ }^{3}$ Não vou aqui analisar o quanto a sua crítica perde em força devido aos possíveis equívocos de sua interpretação da Ética Nicomaqueia. Roger Crisp parece ter razão ao verificar uma noção de obrigatoriedade [notion of a binding morality] também em Aristóteles - com o que a alternativa da ética de virtudes talvez não escapasse a alguns dos resquícios legalistas os quais Anscombe desejaria abandonar. Cf: (ANSCOMBE, 1958; CRISP, 2006), sobretudo o final do primeiro capítulo. Ver também: (SATTLER, 2012).

${ }^{4}$ Evidentemente, fica por se delinear (alhures) o que exatamente significa uma postura anti-metafísica e uma postura anti-teória e anti-normativa em Wittgenstein, ou a partir de Wittgenstein, algo que precisa ser feito com uma caracterização mais robusta do próprio conceito de 'filosofia' no escopo da obra wittgensteiniana (em prol, por exemplo, de uma vida vivida de maneira aproblemática ou pela "paz nos pensamentos") e no escopo dos autores por ela influenciados. Alguns apontamentos neste sentido já constam da análise do Tractatus em (SATTLER, 2014), mas muito mais há por ser feito ao se considerar também a atividade filosófica (terapêutica) das Investigações Filosóficas, além de uma discussão mais aprofundada sobre o sentido mesmo de 'teoria' e, entre outras coisas, 'racionalidade'. - As propostas levadas a cabo neste artigo são propostas iniciais e, obviamente, não conclusivas; lacunas e omissões são, portanto, reconhecidas como tal, e algumas das descrições superficiais relativas aos filósofos aqui citados podem ser completadas com a leitura de outros trabalhos de minha autoria registrados na bibliografia; o preenchimento e o aperfeiçoamento das ideias aqui discutidas é parte dos objetivos do meu presente projeto de pesquisa intitulado Vida Moral e Literatura: Identidade e Engajamento. - Algumas outras notas de rodapé a seguir farão referência a estas observações de sobreaviso.

5 E o procedimento não-argumentativo - pelo menos num sentido que aproxima argumento de justificação e demonstração sistemática - é mais uma característica deste "espírito wittgensteiniano" constitutivo de uma outra metodologia filosófica. Cf., por exemplo: (DIAMOND, 1995).

${ }^{6} \mathrm{Cf}$. as Investigações Filosóficas, $§ 133$ : “A verdadeira descoberta é a que me torna capaz de romper com o filosofar, quando quiser". Obviamente, "acalmar" a filosofia desta maneira só é possível quando os "problemas filosóficos" desaparecem completamente. No que toca às nossas reflexões sobre a moralidade, isto talvez venha a significar o reconhecimento puro e simples de uma irremediável complexidade e, com isso, da impossibilidade de uma sempre almejada fundamentação e normatização universal.

7 Um mapa detalhado de referências é algo que se pode fazer separadamente, do Tractatus às Investigações - no entanto, em outro momento apenas. Cf. igualmente a nota 3 acima.

${ }^{8}$ Expressão usada pelo próprio Wittgenstein ao falar sobre os modos de se proceder ao dar "razões" em ética, estética e filosofia, segundo relato de Moore em Philosophical Occasions: "(...) Reasons, he said, in Aesthetics, are 'of the nature of further descriptions', e.g., you can make a person see what Brahms was driving at by showing him lots of pieces by Brahms, or by comparing him to a contemporary author; and all that Aesthetics does is 'to draw your attention to a thing', to 'place things side by side'. He said that if, by giving 'reasons' of this sort, you make the other person 'see what you see' but 'still doesn't appeal to him', that is 'an end' of the discussion; and that what he, Wittgenstein, had 'at the back of his mind' was 'the idea that aesthetic discussions were like discussions in a court of law', where you try to 'clear up the circumstances' of the action which is being tried, hoping that in the end what you say will 'appeal to the judge'. And he said that the same sort of 'reasons' were given, not only in Ethics, but also in Philosophy." (WITTGENSTEIN, 1993, p.106). 
${ }^{9}$ Que seria o modo próprio de pensar das Investigações Filosóficas; cf. (GAITA, 2013, p.13-14), onde esta expressão é comentada.

${ }^{10}$ Para isso, já ofereci algumas referências anteriormente. Cf. nota 2.

${ }^{11}$ É claro que corremos o risco de uma generalização injusta ao colocarmos kantianos, utilitaristas, principialistas, entre outros, como participantes de uma mesma herança moderna cujos resultados sejam todos fadados ao mesmo tipo de fracasso, devido ao mesmo tipo de razões. No entanto, se reconheço as devidas nuances de um utilitarismo à la Mill, por exemplo, não posso, no escopo deste artigo, abrir espaço para discussão das possíveis e positivas exceções.

${ }^{12}$ As quais me interessa abordar desde um outro ponto de vista, talvez mais próximo de uma ética de virtudes em sua relação com a literatura, e representativo de um certa leitura da vida moral desde uma perspectiva aristotélica (Nussbaum), platônica (Murdoch), e wittgensteiniana (Diamond).

${ }^{13}$ Cujas obras mais representativas para os tópicos aqui privilegiados são: Good and Evil. An Absolute Conception (GAITA 2004), A Common Humanity: Thinking about Love and Truth and Justice (GAITA, 2013), O cão do filósofo (GAITA, 2002); A Philosophical Disease: Bioethics, Culture, and Identity (ELLIOTT, 1999), Slow Cures and Bad Philosophers: Essays on Wittgenstein, Medicine, and Bioethics (ELLIOTT, 2003).

${ }^{14}$ É também por isso que eu mesma faço uso frequente de 'reflexão moral' como forma de traçar uma certa especificidade e diferença relativamente aos termos de 'ética' e 'filosofia moral'; ademais, uma outra distinção ainda - cuja justificativa encontra-se principalmente em (SATTLER, 2014) - permeia o presente artigo no sentido wittgensteiniano segundo o qual a 'ética' é compreendida como pretensa disciplina filosófica constituída de "(pseudo)proposições éticas" (na verdade interditas pela concepção tractariana da linguagem) e a 'moralidade' é o âmbito de uma vivência não apenas legítima (enquanto mostrável), como inescapável. A 'ética', portanto, não se pode dizer; mas a 'moralidade' é condição de possibilidade para o sujeito como limite do mundo.

${ }^{15}$ Penso aqui em obras como $O$ cão do filósofo, de Gaita, e $A$ vida dos animais, de J.M. Coetzee, como exemplos de "narrativas filosóficas". Mas esta não precisa ser uma nomeação estanque, e o próprio nome não precisa necessariamente ser tomado como exigindo uma classificação.

${ }^{16}$ A indissociabilidade entre forma e conteúdo constituindo um traço cuja importância é igualmente enfatizada pelas autoras anteriormente mencionadas. Cf., por exemplo: (NUSSBAUM, 1992, p.03-53).

${ }^{17}$ Expressões usadas, de modo bastante semelhante, por Gaita e Diamond. Cf., por exemplo: (GAITA, 2004, p.341; DIAMOND, 1995, p.294).

${ }^{18}$ Tanto Nussbaum quanto Gibson se valem desta expressão - com diferenças - para estabelecer a relação entre filosofia e literatura. Cf. (NUSSBAUM, 1992, capítulo 9; GIBSON, 2004, pp.109-124). 


\section{Referências}

ANSCOMBE, G.E.M. “Modern Moral Philosophy”, Philosophy 33 (1958), pp. 1-19.

BOUVERESSE, J. Le philosophe chez les autophages. Les Étidions de Minuit, 1984.

CRARY, A. Does the Study of Literature Belong Within Moral Philosophy? Reflections on the light of Ryle's Thought. Philosophical Investigations, vol. 23, n.4, pp.316-350, out 2000.

COETZEE, J.M. A Vida dos Animais. Trad. José Rubens Siqueira. Org. Amy Gutman. São Paulo: Cia das Letras, 2002.

CRISP, R. Reasons \& the Good. Oxford: Oxford University Press, 2006.

DIAMOND, C. “Anything but Argument?", in The Realistic Spirit: Wittgenstein, Philosophy and the Mind. MIT Press, 1995.

ELLIOT, C. A Philosophical Disease: Bioethics, Culture, and Identity. New York: Routledge, 1999.

ELLIOT, C. (Ed.). Slow Cures and Bad Philosophers: Essays on Wittgenstein, Medicine, and Bioethics. Durham: Duke University Press, 2003.

GAITA, R. A Common Humanity: Thinking about Love and Truth and Justice. Routledge, 2013.

GAITA, R. Good and Evil. An Absolute Conception. 2nd ed. Routledge, 2004.

GAITA, R. The Philosopher's Dog. Routledge, 2005.

GIBSON, J. \& Huemer, W. The Literary Wittgenstein. Routledge, 2004.

GIBSON, J. "Reading for Life”. In The Literary Wittgenstein. Gibson, J. \& Huemer, W. (eds.). New York: Routledge, 2004, pp.109-124.

MURDOCH, I. A Soberania do Bem. Tradução Julián Fuks. São Paulo: Editora Unesp, 2013.

NUSSBAUM, M. C. Love's Knowledge. Essays on Philosophy and Literature. Oxford University Press, 1990.

SATTLER, J. "Alternativas à "Filosofia Moral Moderna": Considerações Wittgensteinianas,

Estoicas e Literárias'. In: Ética, Linguagem e Antropologia: Perspectivas Modernas e Contemporâneas. Carmo, J.S. \& Santos, R. (org.). Porto Alegre: EdiPUCRS, 2012. 
SATTLER, J. L'éthique du Tractatus: non-sens, stoïcisme et le sens de la vie. (Série DissertioFilosofia). Pelotas: NEPFIL online, 2014. http://nepfil.ufpel.edu.br/dissertatio/acervo-livro8.php WITTGENSTEIN, L. "A Lecture on Ethics". The Philosophical Review. Vol.74, No. 1, pp.0312, (Jan, 1965).

WITTGEnSteIn, L. Philosophical Investigations. Trans. by G.E.M. Anscombe, P.M.S. Hacker \& J. Schulte. $4^{\text {th }}$ ed. Blackwell Publishing, 2009.

WITTGENSTEIN. L. Philosophical Occasions, 1912-1951. James Carl Klagge \& Alfred Norman (eds.), Hackett Publishing, 1993.

WITTGENSTEIN, L. Tractatus Logico-Philosophicus. Trans. by C.K. Ogden. Routledge, 2005. 